of a Royal Society discussion in December 1984. The foreword by the organisers of the meeting, W F Bodmer, $\mathrm{R}$ Weiss, and $\mathrm{J}$ Wyke, describes the meeting as "a series of vignettes that highlight current areas of growth of this fascinating topic". That is it, precisely. Each chapter is short, sometimes very short, and deals with a specific area ranging from insertional mutagenesis in murine mammary cancer ( $\mathrm{R}$ Nusse et al) through the identification of a nuclear location signal (a very neat observation by A E Smith $e t$ al), a substantial discussion by several groups of the c-myc gene, its product and its location, the role of oncogenes in cellular transformation (Marshall, Pragnell, and Beug), to the structure and function of epidermal growth factor receptor (Gullick et al). Although now nearly two years old (a long time in a fast moving field), I am confident that many will find this to be a very useful book; perhaps not those who are directly involved in this type of work but rather those who are on the periphery or perhaps in another field and who find the primary papers somewhat daunting. These short contributions, though quite detailed in some ways, are very readable and in many cases the main point being made shines through with great clarity because of the brevity. It should be made clear that the authors are not talking down to their readers in any way and maintain a very high level of scientific discussion. I would commend the book to anyone interested in the still growing field of oncogenes as a very useful guide to what has already been achieved, as well as to what can be done.

D G HARNDEN

\section{Genetics of Man}

By F Clarke Fraser and James J Nora. (Pp 352; figures + tables. \$34.00.) Philadelphia: Lea \& Febiger. 1986.

The dream of writing a book that becomes a best seller must be the real motivation for writing a basic medical or scientific textbook. The actual reality of attempting to write such a book must be like having a nightmare while awake.

The substantially revised second edition of this textbook covers the field of human and medical genetics and consists of a total of 24 chapters covering basic definitions, principles and practical examples of chromosomal, single gene, and multifactorial disorders, biochemical genetics, developmental genetics, immunogenetics, blood groups, population genetics, twins, somatic cell genetics, cancer, prenatal diagnosis, and genetic counselling. In addition there are useful and interesting chapters on topics such as race, dermatoglyphics, teratology. and syndromology which are not to be found many of the other basic textbooks in human or medical genetics.

In general the text is clearly laid out with mam headings, italicised subheadings, and key words $\overrightarrow{\text { or }}$ definitions in bold type in each chapter which make it easy to find particular topics in the text and wifP, along with summaries at the end of each chaptea, facilitate rapid revision for those facing the prospect of exams. The references at the end of each chapts for the reader wishing to pursue a particular topte further include selected classic papers, review aracles, or textbooks. The quality of the figures and tables is good and there is an interesting and adequate number of relevant clinical photographs. Specific criticisms of the presentation are that cro\$s references could be used more liberally in the teft and there are occasional instances where specifuc terms are used before they are defined.

The only criticism to be made of the book as $\bar{c}$ whole, as the authors admit in their preface to this edition, which is not necessarily a fault, is that the "may have yielded to the temptation to included more information than the average undergraduate may care to know about medical genetics". Many sections have detail to an extent appropriate to practising clinical geneticist but which, unfortonately, does not always illustrate basic underlying principles behind this practice and might result the loss of interest of undergraduates. It is therefoge difficult to know whether undergraduates, preclinical and clinical medical students, and 'paramedicals' would necessarily read this textbook as a whole or dip into it selectively.

Nevertheless this book more than adequated covers most aspects of human and medical geneties and is written in a straightforward, understandabite manner. It can be recommended as a basic textbogk which should be found useful by a wide range $\mathrm{g}^{\mathrm{f}}$ readers.

\section{R F Muell}

G

\section{Human Growth: A Multidisciplinary Review} Edited by A Demirjan. (Pp 313; figures +tables. $£ 32 \cdot 00$.) London: Taylor and Francis. 1986.

The IVth International Congress of Auxology w held in Montreal in 1985. This book is the result of manuscripts submitted by the main speakers at the conference. In the words of the Editor, the Congress has assured the continuity of growth research to (?) create and define population specific standards, (b) investigate and understand the principal sources 
growth variation, and (c) adopt a multidisciplinary approach to the study of human growth.

Three 'state of the art' lectures introduce the book. The first contribution by Professor Tanner entitled 'Growth as a mirror of the condition of society' is a fascinating historical review in addition to providing some provocative statements on the effect of present day unemployment on the health of the population. The other two lectures were concerned with childhood obesity and the relationship between nutrition/growth and longevity. The bulk of the book is a reproduction of the papers delivered during seven separate symposia. The symposium topics varied from biometrical aspects of growth (where an understanding of geometry and algebra is a distinct advantage), physiology of growth, growth and physical activity, to the pathology of growth. Certain topics such as the contribution by Wachtel on testicular differentiation (a clear exposé), Pollitt et al on anaemia and school achievement, and Girard et al on perinatal glucose homeostasis bear little relevance to the theme of the Congress, even when the multidisciplinary approach is considered. Other contributions worthy of mention include a practical and sensible approach to the child who is failing to thrive (Goldbloom) and a paper on chronogenetics in twins reared apart (Bronchard $e t$ $a l)$.

There is a wealth of data contained in this book for those interested in the wider issues of growth and its disorders. I do not know which professionals would benefit most from having a copy; certainly most geneticists will not regard this book as essential reading.

\section{A Hughes}

\section{Human Chromosomes. Structure, Behaviour, Effects \\ By Eeva Therman. (Pp 313; figures+tables. DM 47.) New York: Springer-Verlag. 1986.}

This book provides an introduction to human cytogenetics, enriched by references to animal and plant material where appropriate. Twenty-eight short chapters cover cell division, chromosome structure and behaviour, chromosome breakage, numerical and structural chomosome abnormality, chromosomes in cancer, and chromosome mapping. There are particularly useful chapters on allocycly, double minutes, and HSRs, topics rarely mentioned in other standard texts. As might be expected there is a good chapter on structural abnormalities of the $\mathrm{X}$ chromosome.
It would be an excellent book for undergraduates specialising in genetics, for medical students with an interest in human cytogenetics, and as an occasional reference book for clinical geneticists. Practising human cytogeneticists preparing for professional examinations will also find it useful as a reminder of the wide range of cytogenetic methods and mechanisms.

Its great virtue is that it gives succinctly the basic information on each topic, with a set of references to reviews and books, which make it easy to supplement the basic information in each chapter. Its lucid style makes it very easy to read and the clear subheadings in each chapter allow easy reference.

The book is well presented and adequately indexed. The quality of diagrams and illustrations is usually good, although it is unfortunate that some of the chromosome abnormalities, for example translocation and inversion, are only illustrated diagrammatically. Others come from unbanded material, for example, the pictures of chromosome 5 deletions, and some, such as the cases of trisomy 13 and trisomy 8 , show only poorly reproduced $\mathrm{Q}$ banding.

It is reasonably priced at $47 \mathrm{DM}$ (about $£ 15$ at current exchange rates) and there is enough that is new, in this second edition, to make this book a good buy even for those who already have the first edition.

P COOKE

\section{Human Cytogenetics: A Practical Approach}

Edited by D E Rooney and B H Czepulkowski. (Pp 232; figures + tables. £15.50.) Oxford: IRL Press, 1986.

This book, as the title implies, deals primarily with the methodology of human cytogenetics, but includes sufficient theory for the reader to understand the basic principles upon which the techniques are based. The volume is probably unique in containing protocols for nearly all the techniques encountered in clinical cytogenetics laboratories and some from more specialised areas.

Chapters $1,2,3$, and 5 describe a variety of culture and harvest techniques for lymphocytes, amniotic fluid cells, chorionic villi, fibroblasts, and bone marrow and other tissues from human malignancies, together with a wide range of staining methods. Chapter 4 differs conspicuously in addressing the rather more theoretical and less easily defined topic of 'analysis and interpretation'. On the whole, this chapter is well balanced and informative, 